\title{
Forecasting water use in selected water supply system
}

\author{
Krzysztof Boryczko ${ }^{1, *}$ \\ ${ }^{1}$ Rzeszow University of Technology, al. Powstancow Warszawy 6, 35-959 Rzeszow, Poland
}

\begin{abstract}
The study analyzed data on water consumption in selected municipal water supply system. The forecast was made based on daily water consumption from the period of five years $(2012 \div 2016)$. The results are a valuable information source for municipal water supply system operator. Water consumption forecast allows to schedule the amount of water that should be produced e.g., taking into account day of the week, month, and the least onerous terms for water consumers to make repair or modernization of water supply system elements.
\end{abstract}

\section{Introduction}

By definition, forecasting, other word: prediction, is the rational prediction of events in a scientific manner. Otherwise, it is a possibility to conclude about so far unknown events based on known events that occurred in the recent past [1]. The primary function of the forecast is to provide the most objective solutions, which relate to the anticipated event occurring in the future [2-4]. Basic functions of the forecasts are [6, 7]:

- dissecting, which creates prerequisites to take rational decisions,

- activating - stimulating to take action that favours the execution of forecast,

- information.

The forecast can be presented in view of the so-called forecast horizon, i.e. the period for which it was made. In this classification we distinguish:

- immediate, direct forecast which does not exceed 1 month,

- short-range forecast, covering 1 - 3 months,

- medium-range forecast which does not exceed 2 years,

- long-range forecast, made for more than 2 years.

Classification of forecasts can also be shown in view of the nature (e.g. simple or complex, single or repeatable, quantitative or qualitative), in view of the degree of details (general or detailed) or in view of the purpose of conducting (research, normative or active or passive) [7].

The issue raised in the work, associated with forecasting, requires an appropriate reference to Polish and foreign literature [7-25]. In recent years, the methods of forecasting rapidly develop and are used in practice more and more often. The essential problem of the subject - forecasting water use, turned out to be sporadically reported in the literature. In the

* Corresponding author: kb@prz.edu.pl 
study we analysed data on water consumption in the municipality in south-east of Poland. Details of daily water consumption, on the basis of which the simulation was made, are for 5 recent years $(2012-2016)$. To forecast water consumption the method of exponential smoothing with seasonal additive was used.

\section{Description of the water supply system}

Water supply system in the municipality includes equipment for taking, treatment and distribution of water for the household, economic and industrial purposes. Municipal water supply system has the radial structure, branched, typical for water supply in rural areas areas characterized by dispersed housing. Water supply system takes water from three underground sources and supplies water to about 16 thousand residents.

Water supply system in the municipality consists of:

- 9 tanks with total capacity $2050 \mathrm{~m}^{3}$.

- main - the length of $2 \mathrm{~km}$, diameters $315 \mathrm{~mm}, 225 \mathrm{~mm}, 160 \mathrm{~mm}$,

- distribution - $158.1 \mathrm{~km}$ length, diameter $110 \mathrm{~mm}, 90 \mathrm{~mm}$.

Whole network is made of PVC.

\section{The method of exponential smoothing with seasonal additive}

The equation describing the exponential smoothing model with additive seasonality:

$$
\left\{\begin{array}{c}
F_{t}=\alpha \cdot\left(y_{t}-C_{t-r}\right)+(1-\alpha) \cdot F_{t-1} \\
C_{t}=\gamma \cdot\left(y_{t}-F_{t}\right)+(1-\gamma) \cdot C_{t-1}
\end{array}\right.
$$

where:

$\mathrm{y}_{\mathrm{t}}$ - the forecast variable at a moment or period of time $\mathrm{t}$,

$\mathrm{F}_{\mathrm{t}}$ - smoothed evaluation of the level (mean value) at a moment or period of time $\mathrm{t}$,

$\mathrm{C}_{\mathrm{t}}$ - evaluation of seasonality index at a moment or period of time $\mathrm{t}$,

$\alpha$ - smoothing parameter of forecast variable level with values from the range $(0,1]$,

$\gamma$ - evaluation parameter of seasonal index with values from the range $(0,1]$,

$\mathrm{r}$ - the length of a seasonal cycle (number of phases of each cycle).

The purpose of equation (1) is to determine a smoothed value of the entire time series and to determine the index of seasonality.

The parameters $\alpha$ and $\gamma$ can not be equal to 0 and the sum of the weights should be equal to one.

The use of this model on the basis of the time series consisting of n-elements relies on calculating the following equation:

$$
y_{t}^{*}=F_{n}+C_{T-r}, \text { for } T=n-1, \ldots, n+1
$$

wherein the coefficients $\mathrm{F}_{\mathrm{n}}$ and $\mathrm{C}_{\mathrm{T}-\mathrm{r}}$ are calculated from the following formula:

$$
\begin{gathered}
F_{n}=\alpha \cdot\left(y_{n}-C_{n-r}\right)+(1-\alpha) \cdot F_{n-1} \\
C_{T-r}=\gamma \cdot\left(y_{T-r}-F_{T-r}\right)+(1-\gamma) \cdot C_{T-2 r}
\end{gathered}
$$

To perform the forecast, the necessary are values $F_{n}$ and $C_{n}$, which are dependent on the $\mathrm{F}_{\mathrm{n}-1}$ and $\mathrm{C}_{\mathrm{n}-\mathrm{r}}$. When calculating the forecast $\mathrm{y}_{\mathrm{t}}{ }^{*}$ the expired forecasts must be determined: 


$$
y_{t}^{*}=F_{t-1}+C_{t-r}, \text { for } t>r
$$

where:

$$
\begin{gathered}
F_{t-1}=\alpha \cdot\left(y_{t-1}-C_{t-1-r}\right)+(1-\alpha) \cdot F_{t-2} \\
C_{t}=\gamma \cdot\left(y_{t}-F_{t}\right)+(1-\gamma) \cdot C_{t-r}, \text { for } 2 r \geq t>r \\
C_{t-r}=\gamma \cdot\left(y_{t-r}-F_{t-r}\right)+(1-\gamma) \cdot C_{t-2 r}, \text { for } t>2 r
\end{gathered}
$$

Before the calculation, the initial values $C_{1}, \ldots, C_{r}$ and $F_{r}$ should be taken. The values should be adopted for the first cycle in accordance with the equation:

$$
C_{i}=y_{i}-\frac{y_{1}+\ldots+y_{r}}{r}, \text { for } i=1, \ldots, r
$$

The total sum of values of $\mathrm{C}_{1}, \mathrm{C}_{2}, \ldots, \mathrm{C}_{\mathrm{r}}$ should be equal to 0 :

$$
\sum_{i=1}^{r} C_{i}=0
$$

Value $\mathrm{F}_{\mathrm{r}}$ is calculated according to the expression:

$$
F_{r}=\frac{y_{1}+\ldots+y_{r}}{r}
$$

\begin{tabular}{|c|c|c|c|c|c|c|c|}
\hline no. & day & month & water consumption, $y$ & $\mathbf{F}_{\mathrm{t}}$ & $\mathrm{C}_{\mathrm{t}}$ & $y_{t}^{*}$ & \\
\hline 1 & 1 & \multirow{15}{*}{ 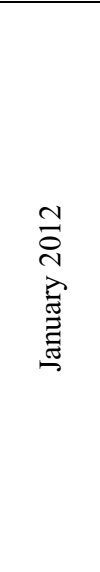 } & 936 & - & -161 & - & \multirow{6}{*}{$y_{8}^{*}=F_{8}+C_{1}$} \\
\hline 2 & 2 & & 381 & - & \begin{tabular}{|l|}
-191 \\
\end{tabular} & - & \\
\hline 3 & 3 & & 1228 & - & 53 & - & \\
\hline 4 & 4 & & 980 & - & -167 & -2 & \\
\hline 5 & 5 & & 1552 & - & 405 & $7-$ & \\
\hline 6 & 6 & & 961 & - & -108 & - & \\
\hline 7 & 7 & & 1042 & 1097 & 113 & - & \\
\hline 8 & 8 & & 1458 & \begin{tabular}{|l|l}
1202 \\
\end{tabular} & 48 & 936 & \\
\hline 9 & 9 & & 1005 & 1200 & -193 & 1011 & \\
\hline 10 & 10 & & 1032 & 1156 & -36 & 1253 & \\
\hline 11 & 11 & & 981 & 1155 & -170 & 989 & \\
\hline 12 & 12 & & 987 & 1040 & 176 & 1559 & \\
\hline 13 & 13 & & 883 & \begin{tabular}{|l|}
1030 \\
\end{tabular} & -126 & 935 & \\
\hline 14 & 14 & & 810 & 989 & -96 & 1016 & \\
\hline 15 & 15 & & 1396 & 1060 & 192 & 1036 & \\
\hline
\end{tabular}

Table 1. shows the mechanism of calculations using EXCEL.

$$
F_{7}=\frac{y_{1}+y_{2}+y_{3}+y_{4}+y_{5}+y_{6}+y_{7}}{r}
$$

$$
C_{1}=y_{1}-\frac{y_{1}+y_{2}+y_{3}+y_{4}+y_{5}+y_{6}+y_{7}}{r}
$$

Table 1. The mechanism of calculation 


\begin{tabular}{|c|c|c|c|c|c|c|}
\hline 1462 & 1 & $\exists=$ & 745 & 1024 & -32 & 1361 \\
\hline 1463 & 2 & & 1049 & 1079 & -142 & 770 \\
\hline
\end{tabular}

\begin{tabular}{|c|c|c|c|c|c|c|c|}
\hline 1822 & 27 & \multirow{5}{*}{ 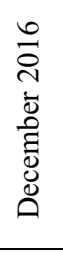 } & 1020 & 1216 & -143 & 1153 & \multirow{6}{*}{$y_{1827}^{*}=F_{1826}+C_{1462}$} \\
\hline 1823 & 28 & & 1307 & 1233 & 39 & 1220 & \\
\hline 1824 & 29 & & 1112 & 1214 & -63 & 1210 & \\
\hline 1825 & 30 & & 1126 & 1171 & 40 & 1340 & \\
\hline 1826 & 31 & & 1301 & 1153 & 184 & 1391 & \\
\hline \multicolumn{7}{|c|}{ Forecast } & \\
\hline 1827 & 1 & \multirow{4}{*}{ 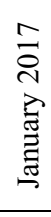 } & - & - & - & 991 & \multirow{7}{*}{$y_{1828}^{*}=F_{1826}+C_{1463}$} \\
\hline 1828 & 2 & & - & - & - & 882 & \\
\hline 1829 & 3 & & - & - & - & 1189 & \\
\hline 1830 & 4 & & - & - & - & 912 & \\
\hline 1831 & 5 & & - & - & - & 902 & \\
\hline 1832 & 6 & & - & - & - & 963 & \\
\hline 1833 & 7 & & - & - & - & 1099 & \\
\hline
\end{tabular}

\section{Forecasting water consumption in selected municipality}

Data on water consumption for the period $2012 \div 2016$ and the forecast for 2017 are characterized by fluctuations in water consumption with clearly shaping seasonality in the summer months.

Table 2 shows the average value of the data (on the basis of which the forecast for 2012 $\div 2016$ was carried out) for each day of the week.

Table 2. Average value of the water consumption, variations, mean deviation for $2011-2015$.

\begin{tabular}{|c|c|c|c|}
\hline day of the week & water consumption, $\mathbf{~ m}^{\mathbf{3}}$ & $\boldsymbol{\sigma}^{\mathbf{2}}$ & $\boldsymbol{\sigma}$ \\
\hline Mon & 1044 & 94288 & 307 \\
\hline Tue & 1196 & 106206 & 326 \\
\hline Wed & 1200 & 100183 & 317 \\
\hline Thu & 1210 & 105111 & 324 \\
\hline Fri & 1200 & 112284 & 335 \\
\hline Sat & 1187 & 138509 & 372 \\
\hline Sun & 1557 & 118600 & 344 \\
\hline
\end{tabular}

On the basis of Table 2, it can be observed that the increase in water consumption took place at the weekend and the highest value for the week was reached on Sunday. This is due to lifestyle of the recipients - the longer time spent at home, compared to weekdays, and house chores. Then, on Monday, water consumption was reduced from $1557 \mathrm{~m}^{3}$ to $1044 \mathrm{~m}^{3}$, and successively during a week it was about $1,200 \mathrm{~m}^{3}$.

Four years data was used for building the model and forecast for 2016 was made to compare it the forecasted data with historical data from 2016 (Fig. 1). 


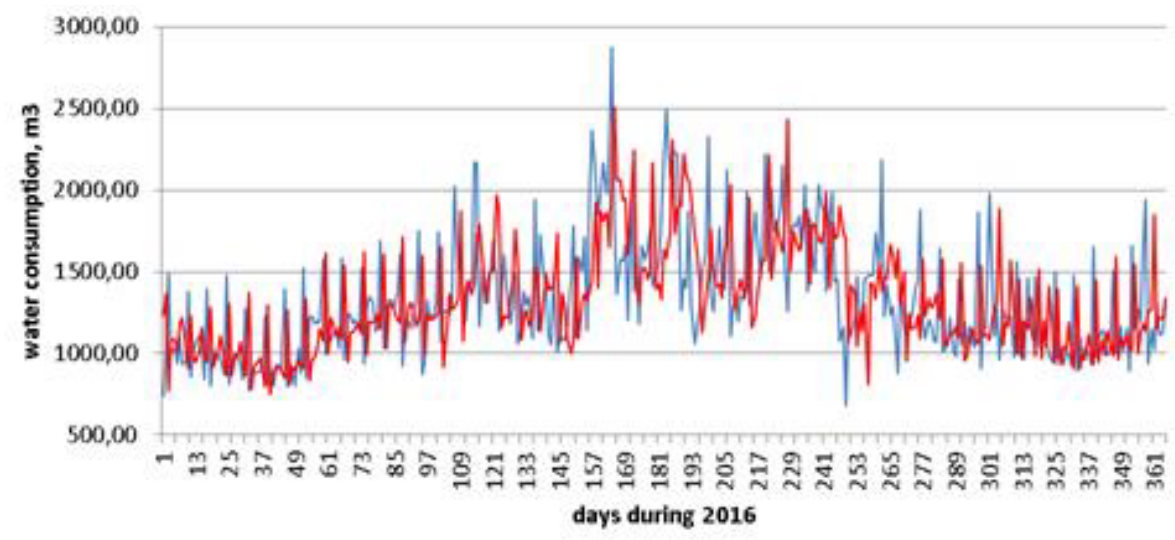

- water consumtion 2016 - forecast for 2016

Fig. 1. Average water consumption during forecast period (2017).

Prepared model correctly predicts future water consumption. Figure 2 presents water consumption forecast for 2017.

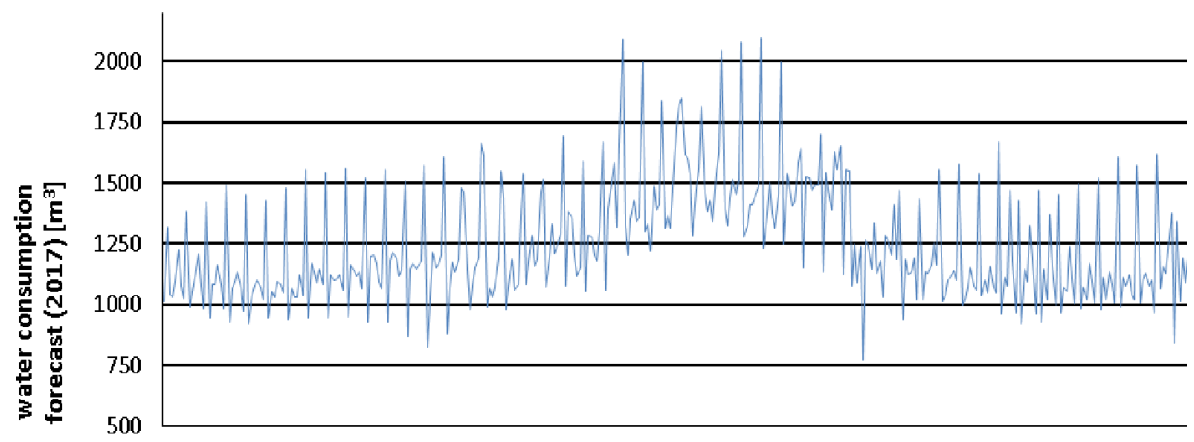

Fig. 2. Average water consumption during forecast period (2017).

For comparison, the same data as Table 2. was created for the forecast of water consumption for 2017 on Fig. 3.

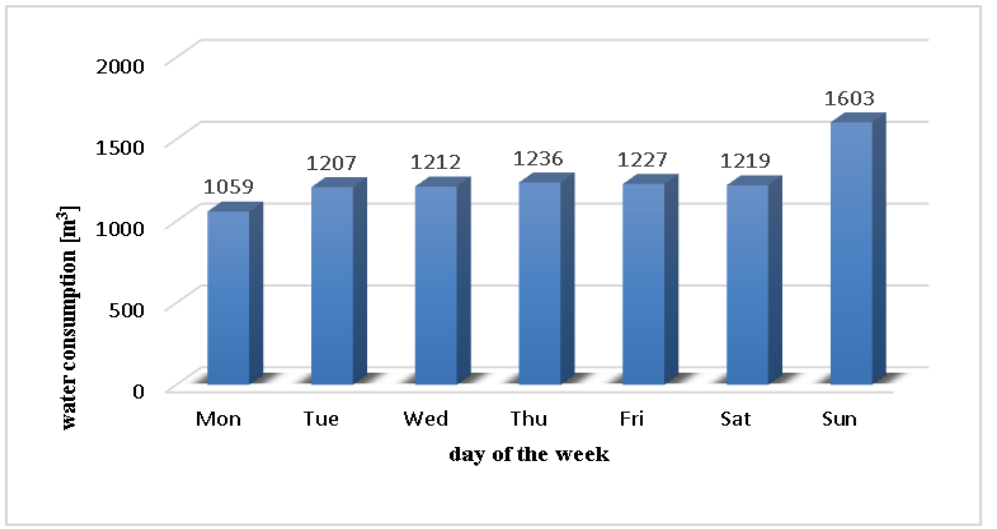

Fig 3. Average water consumption during forecast period (2017). 


\section{Conclusions}

Data on water consumption for the period 2012-2016 and the forecast for 2017 are characterized. After analysing the results and comparing them to the previous water consumption, it was stated that the forecasting model was correct. The results of the method of exponential smoothing with seasonal additive as well as water consumption in the past, oscillate around the trend line and the apparent increase in water consumption also takes place during the summer (May-August).

The method meets the principle of the easy availability of output data that is convenient from a practical point of view. These data do not include external factors (for example environmental) - variables, but they are based on chronological data of the past.

In summary, this paper presents a model of the time series, which is a simple and flexible tool for forecasting. The basic argument, which supports the use of the above models is mainly good quality of water consumption forecast and hence a better quality of water distribution services. With the appropriate series of past data forecasting demand for water is possible. Choice of the correct methods and properly conducted forecast allow to draw the appropriate conclusions, thanks to which it is possible to improve the operation of water supply systems.

The paper presents the simple forecasting model that is a universal and fast tool to predict the demand for water in water supply system on the basis of the collected data. Additionally described model can be used during the operation of the water companies to plan, among others:

- the purchase of reagents for treatment

- repairs related to the shutdown of water supply

- costs of pumping water.

\section{References}

1. B. Pawełek, A. Zeliaś, S. Wanat, Prognozowanie ekonomiczne, Teoria przykłady zadania (Wydawnictwo Naukowe PWN, Warszawa, 2003)

2. K. Pietrucha-Urbanik, B. Tchórzewska-Cieślak, M. Urbanik, Analysis of the gas network failure and failure prediction using the Monte Carlo simulation method, Eksploat Niezawodn 18, 254-259 (2016)

3. K. Pietrucha-Urbanik, Failure analysis and assessment on the exemplary water supply network, Eng Fail Anal 57, 137-142 (2015)

4. J.P. Leitao, A. Martins, C. Amado, Comparative Study of Three Stochastic Models for Prediction of Pipe Failures in Water Supply Systems, J Infrastruct Syst 19, 442-450 (2013)

5. X. Jing, An integrated prediction model for water supply-demand ability, 4th International Conference on Advanced Materials and Information Technology Processing (AMITP), ACSR-Advances in Comptuer Science Research, Guilin, 2016, 60, 528-531.

6. J. Han, The Analysis and Prediction of Water Supply and Demand for Beijing in future, 3rd International Conference on Education, Management and Computing Technology (ICEMCT), Advances in Social Science Education and Humanities Research, Hangzhou, 2016, 59, 1050-1053

7. J. Łomotowski, Z. Siwoń, W. Cieżak, P. Licznar, J. Cieżak, Analizy i prognozowanie rozbiorów wody w systemach wodociagowych (Komitet Inżynierii Lądowej i Wodnej PAN, Warszawa, 2008)

8. J. Ciezak, W. Ciezak, Routine forecasting of the daily profiles of hourly water distribution in cities. An effectiveness analysis, Environ Prot Eng 41, 179-186 (2015) 
9. Z. Siwoń, W. Cieżak, J. Cieżak, Water demand modeling for housing estates, Och Śr 30, 23-28 (2008).

10. J. Cieżak, Z. Siwoń, W. Cieżak, Praktyczne aspekty badań strat wody $w$ sieciach wodociagowych, Och Śr 4, 25-30 (2004)

11. A. Studzinski, K. Pietrucha-Urbanik, Analysis of water pipe breakage in Krosno, Poland, Environmental Engineering IV, Dudzińska M. R. Pawłowski L., Pawłowski A., Editor, London: Taylor \& Francis Group, 59-62 (2013)

12. B. Tchórzewska-Cieślak, D. Szpak, A Proposal of a Method for Water Supply Safety Analysis and Assessment, Och Śr 37, 43-47 (2015)

13. B. Tchórzewska-Cieślak, Urban Water Safety Management, Chemical Engineering Transactions, V; DeRademaeker Cozzani, E; Pierucci, S; Klemes, JJ, Editor, Milano, ITALY: AIDIC SERVIZI SRL, 201-206 (2012)

14. B. Tchórzewska-Cieślak, Estimating the acceptance of bearing the cost of the risks associated with the management of water supply system, Och $\mathrm{Sr}$ 29, 69-72 (2007)

15. J. Rak, B. Kucharski, Slude management in water treatment plants, Environ Prot Eng 35, 15-21 (2009)

16. K. Boryczko, B. Tchórzewska-Cieślak, I. Piegdoń, Possibilistic risk analysis of failure in water supply network, Safety and Reliability: Methodology and Applications, Nowakowski et al. (Eds), Editor, London: Taylor \& Francis Group, 1473-1480 (2015)

17. K. Boryczko, Water age in the water supply network as health risk factor associated with collective water supply, Ecol Chem Eng A 23, 33-43 (2016)

18. A. Kotowski, B. Kaźmierczak, M. Wdowikowski, Trend Analysis of Annual and Seasonal Precipitation Amounts in the Upper Odra Catchment, Och Sr 36, 49-54 (2014)

19. M. Kutylowska, Neural network approach for failure rate prediction, Eng Fail Anal 47, 41-48 (2015)

20. A. Studzinski, K. Pietrucha-Urbanik, Selected issues of costs and failure of pipes in an exemplary water supply system, Rocz Ochr Sr 18, 616-627 (2016)

21. L. Liu, B. Wang, G. H. Huang, et al., Forecast-based analysis for regional water supply and demand relationship by hybrid Markov chain models: a case study of Urumqi, China, J Hydroinform 18, 905-918 (2016)

22. K. Boryczko, A. Pasierb, Method for forecasting the failure rate index of water pipelines Environmental Engineering V, M. Pawlowska, L. Pawłowski Editor, London: Taylor \& Francis Group, 15-24 (2017)

23. J. Kaleta, D. Papciak, A. Puszkarewicz, Removal of Ammonia Nitrogen from Groundwater on Chalcedony Deposits in Two-stage Biofiltration Process, Rocz Ochr Sr 15, 1352-1366 (2013)

24. B. Tchórzewska-Cieślak, K. Boryczko, Analysis of risk of failure in water main pipe network and of developing poor quality water, Environ Prot Eng 40, 77-92 (2014)

25. J. Bajer, Economical and reliability criterion for the optimization of the water supply pumping stations designs, Environmental Engineering IV, Dudzińska M. R. Pawłowski L., Pawłowski A., Editor, London: Taylor \& Francis Group,jhio9yu6j 21-28 (2013)

26. E. Szymura, I. Zimoch, Operator reliability in risk assessment of industrial systems function, Przem Chem 93, 111-116 (2014) 